epicarditis in the newborn. Report of three cases. Arch Pathol 1969 ; 88: 459-62.

11 Forget P, Eggermont E, Marchal G, Geboes K, Jaeken J, Melchior S. Eosinophilic infiltration of the oesophagus in an infant. Acta Paediatr Belg 1978; 31 : 91-3.

12 Pedersen L M, Tygstrup I. Cell infiltration in the pancreas of newborn infants of diabetic mothers. Acta Pathol Microbiol Scand 1968; 73: 537-48.
13 Eitzman D V, Smith R T. The nonspecific inflammatory cycle in the neonatal infant. Am J Dis Child 1959; 97: 326-34.

Correspondence to $\operatorname{Dr} S$ M Murray, Department of Pathology, Victoria Hospital, Blackpool FY3 8NR.

Received 29 January 1980.

\title{
Spontaneous oesophageal rupture with duodenal atresia in a newborn infant
}

\author{
HAJIME NAKAMURA, YOSHIHIKO KANAZAWA, MASAKI HAYANO, AND \\ SHINICHIRO MIMASU
}

Department of Paediatrics, Kobe University School of Medicine, Japan

\begin{abstract}
SUMMARY A newborn infant with spontaneous oesophageal rupture associated with duodenal atresia is described. The diagnosis was established by the pattern of hydropneumothorax on the chest $x$-ray film and by the aspiration of gastric juice by thoracocentesis. Necropsy showed a tear, which extended from the oesophagogastric junction to the upper portion of the stomach.
\end{abstract}

Spontaneous oesophageal rupture in infancy is rare, but it is important to differentiate it from any other disease that causes serious respiratory distress or cyanosis shortly after birth. Since 1952, when the first case of oesophageal rupture was reported, ${ }^{1}$ only 14 cases have been cited. ${ }^{2-3}$ The disease shows a pattern of hydropneumothorax, a finding characteristic on chest $x$-ray films. It should therefore not be too difficult to make an early diagnosis if one knows of the existence of the disease. Some patients survive early surgical operation.

\section{Case report}

A Japanese boy was born after 38 weeks' gestation after induction for hydramnios. Delivery had been spontaneous with a vertex presentation. Birthweight was $2.75 \mathrm{~kg}$ and he was the first child of a 26-year-old mother. He cried spontaneously and required no resuscitation. Mucus was suctioned from the nose and nasopharynx, but no tube was passed into the oesophagus. Three hours after birth, breathing was noted to have become laboured and he was placed in an oxygen tent. By 19 hours, the infant was spitting small amounts of bright red blood and the respiration was rapid, shallow, and grunting. He was transferred to this hospital.

On initial examination he was moribund, in severe respiratory distress, with pronounced cyanosis and cold extremities. The abdomen was distended and movement was diminished on the right side of the chest. Petechiae were found on the chest and abdominal walls. Plain $x$-ray film showed tension hydropneumothorax on the right (Figure). In addition, the stomach and duodenum were distended, distal to which no gas was seen. Thoracocentesis was performed; considerable amounts of air and $30 \mathrm{ml}$ of bile-stained fluid were obtained. Respiratory effort was poor and he received assisted ventilation: $\mathrm{pH} 6 \cdot 98, \mathrm{PaO}_{2} 94 \mathrm{mmHg}(12.5 \mathrm{kPa})$, $\mathrm{PaCO}_{2} 56 \mathrm{mmHg}(7 \cdot 4 \mathrm{kPa})$, base excess $-16 \mathrm{mmol} / 1$. At age 24 hours, a general haemorrhagic tendency and sclerema neonatorum were noted. After exchange transfusion with fresh heparinised blood, the tendency to bleed and the metabolic acidosis, as well as his general condition were improved, but an $x$-ray film showed pneumoperitoneum.

At age 92 hours, laparotomy was performed through an upper midline incision. Purulent matter was attached to the upper portion of lesser curvature of stomach. When the stomach was pulled down, a longitudinal rupture $1.5 \mathrm{~cm}$ in length was found in the anterolateral aspect of the lower end of the oesophagus, spanning the diaphragmatic hiatus and extending to the stomach. The rupture was closed. Atresia of the duodenum was found, the second portion of which ended blindly at an annular pancreas. A duodenojejunostomy was fashioned. A gastrostomy was performed for feeding. The infant tolerated the procedures and chest $x$-ray showed 


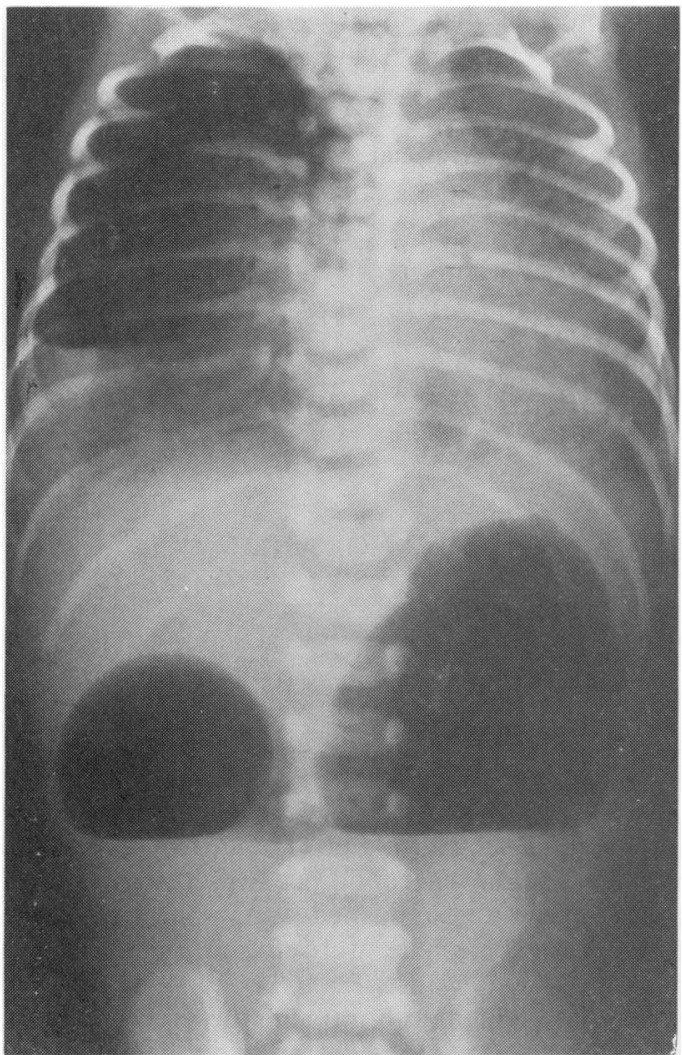

Figure Initial $x$-ray in the erect position showing tension hydropneumothorax on the right. Stomach and duodenum were distended, distal to which no gas was seen.

expansion of the right lung. Subsequently however, there was cardiac failure and he died 43 hours after the operation.

Necropsy was done 4 hours after death. Examination showed the tear which extended from the oesophagogastric junction to the upper portion of the stomach which was covered with coagulum, and duodenal atresia with imperfect fusion of pancreas. Microscopical examination showed the invasion of the gastric folds into the oesophagogastric junction and the presence of diverticula in the submucosal layer. Ulceration and defect of the mucous membrane could be seen surrounding the site of the tear. Hypoplasia of oesophageal and gastric mucosal epithelium and muscle was not found. Inflammatory changes were pronounced in the serosal surface.

\section{Discussion}

As distinct from rupture by trauma, spontaneous oesophageal rupture is said to be caused by a rise in the pressure of the oesophagus due to violent vomiting in the adult. ${ }^{4}$ One cause of this complication in babies is thought to be the intrauterine pressure applied at delivery as the disease develops shortly after birth, or at least within 48 hours of it. Our patient had duodenal atresia and hydramnios; since the child was born with his stomach filled with amniotic fluid, greater pressure than usual appears to have been applied to the stomach and oesophagus. Aaronson et al. ${ }^{2}$ likewise reported a case of spontaneous oesophageal rupture associated with duodenal atresia. In our patient moreover, there was an extension of the gastric folds at the oesophagogastric junction and diverticulae were present in the submucosal layer; both these provide conditions for easy rupture. ${ }^{5}$

Hydropneumothorax on the chest $x$-ray film help to diagnose this disease. Contrast medium flowing out of the oesophagus into the thorax establishes the diagnosis and, at the same time, identifies the site of rupture. Our patient was clearly diagnosed as having a rupture at the lower end of the oesophagus because thoracocentesis aspirated gastric juice mixed with bile from the right thorax. In addition the air was seen passing into the abdominal cavity during the course of screening. Rupture into the pleural cavity is generally on the right side.

In our patient there was a general haemorrhagic tendency, severe metabolic acidosis, and respiratory distress since admission, and surgical operation for closure was performed later. In previous reports, 3 of 11 patients who had undergone surgical operation for closure died. All 3 patients who had been treated by drainage alone died, which implies the need to perform the surgical operation for closure early.

\section{References}

1 Fryfogle J D. In discussion of Anderson R L. Rupture of the esophagus. J Thorac Surg 1952; 24: 387.

2 Aaronson I A, Cywes S, Louw J H. Spontaneous esophageal rupture in the newborn. J Pediatr Surg 1975; 10: 459-66.

3 Murakami T, Sakai K, Kubota H, Takagi S, Satake Y. A case of spontaneous rupture of the esophagus in a newborn infant (in Japanese). Kyobu Geka 1973; 26: 348-53.

4 Anderson R L. Rupture of the esophagus. J Thorac Surg 1952; 24: 369-88.

5 Desorgher G, Bayart M. Perforation spontanée du bas oesophage chez un nouveau-né. Ann Chir Infant 1972; 13: 17-21.

Correspondence to Dr Hajime Nakamura, Department of Paediatrics, Kobe University School of Medicine, Kusunokicho, 7-chome, Ikuta-ku, Kobe, Japan.

Received 13 November 1979 